\title{
Determination of Blood Parameters using Scanning Electron Microscopy as a Prototype Model for Evaluating the Effectiveness of Radiation Therapy for Cervical Cancer
}

\author{
S. N. Mamaeva, $\mathrm{PhD}^{1}$; I. V. Kononova, $\mathrm{PhD}^{2 *}$; V. A. Alekseev'² N. A. Nikolaeva ${ }^{1}$; \\ A. N. Pavlov ${ }^{1}$; M. N. Semenova ${ }^{1.3}$; G. V. Maksimov, PhD, ScD ${ }^{4,5}$ \\ ${ }^{I}$ M.K. Ammosov North-Eastern Federal University, Medical Institute, Yakutsk, Russia \\ ${ }^{2}$ Yakut Scientific Center of Complex Medical Problems, Yakutsk, Russia \\ ${ }^{3}$ Republican Oncology Dispensary, Yakutsk, Russia \\ ${ }^{4}$ Lomonosov Moscow State University, Moscow, Russia \\ ${ }^{5}$ National University of Science and Technology MISiS, Moscow, Russia
}

\begin{abstract}
Using the method of SEM in patients with cervical cancer (CC) during radiation therapy (RT) revealed differences in the size and morphology of nanoparticles (NPs) localized on the outer surface of the erythrocyte membrane. We found that NP-V ("viruses") objects localized on the surface of the erythrocyte membrane of CC patients before RT have more distinct contours and are smaller in comparison with the number of NP-EV (extracellular vesicles) arising during RT. Our previous study showed that NP-V objects are evenly distributed not only on the surface of erythrocytes but also in blood plasma, and that during the RT the amount of NP-V decreases, while NP-EV both increases and decreases. The linear size of the NP-EV is characterized by a Gaussian distribution, while the NP-V has a normal size distribution in certain ranges with different mean values. We found that the number of NP-Vs having different linear dimensions differ significantly. Using X-ray radiation, we established characteristic elemental composition of NP. The PCR method was used to determine the HPV DNA in blood samples from CC patients. The revealed differences in the morphology and composition of NP, as well as the data of PCR analysis, possibly indicate their different nature and can be used as a criterion for assessing the effectiveness of RT and the recovery period.(International Journal of Biomedicine. 2021;11(1):32-38.)
\end{abstract}

Key Words: scanning electron microscopy $\bullet$ cervical cancer $\bullet$ extracellular vesicle $\bullet$ nanoparticle

For citation: Mamaeva SN, Kononova IV, Nikolaeva NA, Pavlov AN, Semenova MN, Maksimov GV. Determination of Blood Parameters using Scanning Electron Microscopy as a Prototype Model for Evaluating the Effectiveness of Radiation Therapy for Cervical Cancer. International Journal of Biomedicine. 2021;11(1):32-38. doi:10.21103/Article11(1)_OA6

\section{Abbreviations}

CC, cervical cancer; EV, extracellular vesicle; HPV, human papillomavirus; NP, nanoparticle; RT, radiation therapy; RBC, red blood cell; SEM, scanning electron microscopy; PCR, polymerase chain reaction.

\section{Introduction}

The increase in relapses or the further development of oncological diseases after a course of therapy, including a course of radiation therapy (RT), poses a challenge for researchers to develop diagnostics for the effectiveness of therapy.

In this paper, we consider the problem of analyzing a set of blood parameters of patients diagnosed with cervical cancer (CC) for a new methodology for determining the effectiveness of RT. Changes in the morphology of erythrocytes under the influence of ionizing radiation during RT were studied using a SEM.

Previously, an SEM has detected nanoparticles (NPs) on the RBC surface in the study of blood samples of CC patients during RT. ${ }^{(1,2)}$ According to their size, the detected NPs probably corresponded to both V ("viruses")(1) and EV (extracellular vesicle) ${ }^{(2)}$ on the cell surface. Changes were 
found in the morphology of erythrocytes of CC patients, as well as in the number and size of NPs found on their surface at different stages of RT. Probably, the action of ionizing radiation affects the state of erythrocyte membranes, which is manifested in changes in their morphology and the appearance of NP-EV on the cell surface. It is important that the diameter of the erythrocytes of patients with $\mathrm{CC}$ is higher than in the control. The total number of poikilocytes increased by about $1 \%$ at each stage of RT. The number of NPs increased at each stage of RT and decreased after the end of RT. The SEM allowed determining erythrocyte agglutination after RT.

Obviously, the results obtained can serve as a basis for the development of indicators for the effectiveness of RT in CC. On the other hand, the nature and process of NP formation on the erythrocyte surface, the number of which changes during RT, requires further research. Our approach will allow monitoring the effectiveness of RT and explaining the causes of recurrence and further development of the disease.

Previously, we gave examples of the presence of EVs in the bodily fluids of cancer patients, including patients with $\mathrm{CC}^{(2-}$ 4) EVs (exosomes, microvesicles, and apoptotic bodies), the sizes of which vary in diameter from $30 \mathrm{~nm}$ to $2000 \mathrm{~nm}$, are defined as membrane particles formed on the surface by a cell of any type. ${ }^{(5-7)}$ Some studies ${ }^{(8-9)}$ have led to the conclusion that the presence of exosomes in the blood of cancer patients stimulates changes in the surrounding healthy cells, ${ }^{(10)}$ which indicates the role of exosomes in the transmission of molecular messages from the parent cell to the target cell. ${ }^{(4,11,12)}$ It is assumed that RT aggravates this process in healthy cells by increasing the EV level, ${ }^{(13)}$ which in turn may be mediated by their stimulating effect. ${ }^{(13-16)}$

These studies indicate the need for a more detailed study of various blood parameters, including the EV number, as biomarkers of cancer progression. In addition, the presence of NPs on the RBC surface, not only in cancer patients, but also in patients with kidney diseases, ${ }^{(1)}$ may also indicate the development of certain viral diseases.

What is the nature of these NPs? Are these NP viruses, vesicles, or are we seeing both? And if we observe both viruses and vesicles, then how to distinguish them?

In the present study, we used SEM and PCR techniques to study NPs found on the RBC surface in patients with CC receiving $\mathrm{RT}$ based on our assumption that they may be cellular EV or viruses.

\section{Materials and Methods}

\section{Blood Samples}

Smears of venous blood containing K3-EDTA from 16 patients with $\mathrm{CC}$ were obtained. The age range was from 45 to 55 years. For $4 \mathrm{CC}$ patients, analyses were taken at the beginning and at each stage of the full course of treatment, and for the remaining $12 \mathrm{CC}$ patients, at the beginning and right after the first stage of RT. For the SEM examination, a thin, even layer of blood was smeared onto a clean degreased glass slide and dried.

To conduct a blood test by PCR, 20 blood samples were prepared from 6 patients with CC who did not undergo RT.

$\underline{\text { Blood fractionation }}$
Blood samples were centrifuged at $1600 \mathrm{~g}$ for 10 minutes. After fractionation, samples of plasma (Pl) and buffy coat $(\mathrm{BC})$ were placed into clean $1.5 \mathrm{ml}$ tubes. The $\mathrm{BC}$ samples were further purified from erythrocytes several times using RBC lysis solution and centrifugation until a pure white precipitate was obtained. After that, a few microliters of phosphate buffer (PBS) were added to the sediment. A fraction of erythrocytes with a volume of $1 \mathrm{ml}$ was transferred into a 15 $\mathrm{ml}$ tube and $14 \mathrm{ml}$ of phosphate buffer was added to it. After gentle mixing, the tubes were centrifuged for 10 minutes at $500 \mathrm{~g}$, draining the supernatant every time after centrifugation. The procedure for washing erythrocytes was repeated three times. After the last wash, half of the remaining suspension was transferred into a clean $1.5 \mathrm{ml}$ tube. It was assumed that the bulk of the erythrocytes is associated with viral particles; therefore, the samples of the erythrocyte fraction after washing were marked as Et+.

For the dissociation of viral particles from the surface of erythrocytes, $0.25 \%$ trypsin solution was added to the remaining half of the suspension in a volume ratio of 1:3. After incubation at $37^{\circ} \mathrm{C}$ for 10 minutes, the suspension was vigorously stirred for 10 seconds. Next, the suspension was centrifuged at $4000 \mathrm{rpm}$ for 10 minutes. The resulting centrifugation top layer was transferred to a clean tube labeled $\mathrm{V}+$, since this was where the virus particles were supposed to be concentrated. The erythrocyte sediment was repeatedly washed with a large volume of phosphate buffer, to remove the remainder of viral particles from the suspension, and then transferred into a clean $1.5 \mathrm{ml}$ tube marked Et- (erythrocytes without viral particles). All samples obtained were stored at $-20^{\circ} \mathrm{C}$ until further use.

\section{DNA extraction}

For DNA extraction, $200 \mu \mathrm{l}$ of previously prepared samples with markings Pl, Et+, Et-, and V+ were used. Phenol and chloroform were added to each sample in an amount of $1000 \mu \mathrm{l}$ and $200 \mu \mathrm{l}$, respectively. After vigorous stirring for 15 seconds, the samples were centrifuged at $13000 \mathrm{rpm}$ for 10 minutes. After centrifugation, the upper liquid phase was carefully transferred to a clean tube and cold isopropanol was added to precipitate the DNA. For better precipitation, the samples were incubated at $-20^{\circ} \mathrm{C}$ for an hour, after which they were centrifuged at $13000 \mathrm{rpm}$ for 10 minutes. After centrifugation, the supernatant was carefully discarded, and the tubes were gently inverted on filter paper to remove the remaining liquid. Then the precipitates were dried in a vacuum for 2 minutes. DNA was dissolved in $50 \mu \mathrm{l}$ TE buffer. The concentration and quality of the isolated DNA were assessed using an Implen P330 Nanophotometer.

\section{$\underline{\text { PCR }}$}

To detect HPV particles, primers GP5+/6+(GP5+: 5'-TTTGTTACTGTGGTAGATACTAC-3' and GP6+: 5'-GAAAAATAAACTGTAAATCATATTC-3' $)^{(17,18)}$ and MY09/11(MY09: 5'CGTCCMARRGGAWACTGATC3' and MY11: 5'-GCMCAGGGWCATAAYAATGG-3') ${ }^{(19-22)}$ were used to detect a wide range of HPVs and aimed at detecting the viral gene $L 1$. A region of the $\beta$-globin gene amplified with primers $\mathrm{PC} 03 / 04$ (PCO3: 5'-CTTCTGACACAACTGTGTTCACTAGC-3 'and PCO4: 5'-TCACCACAACTTCATCCACGTTCACC-3') was 
used as an internal control and confirmation of the presence of human DNA. To check the reliability of PCR, the products of amplification were separated by electrophoresis in $2 \%$ agarose gel.

$\underline{\text { SEM images and elemental analysis }}$

An SEM was used to study the morphology and surface of erythrocytes in patients with cervical cancer at the beginning, after the first and second (final) stages of RT (external and contact, respectively). We used a high-resolution JSM-7800F SEM(Japan Electron-Optical Laboratory, JEOL, Japan) equipped with a Schottky thermal field emission cathode and a super hybrid objective lens. The microscope is equipped with the Gentle Beam system, which reduces which reduces the speed of electron propagation of the emission beam and allows obtaining high-quality images of biological samples at low accelerating voltages. The following microscope parameters make it possible to study the morphology of the RBC surface in blood smears without spraying conductive coatings, to eliminate damage to the object, and to identify NPs (resolution of $1.2 \mathrm{~nm}$ ): magnification range $1-100,000$ at voltage of $1 \mathrm{kV}-2 \mathrm{kV}$.

The maximum sample size was $20 \mathrm{~mm}$. The analysis of the NP sizes was carried out using the software JMicroVision v1.2.7 (Roduit, 2007).

An additional SEM module (Oxford INCA Energy 350 energy dispersive microanalysis system) was used to conduct elemental analysis of NP on the surface of erythrocytes and on plasma. The principle of operation of the microanalyzer is based on the method of X-ray microanalysis, the essence of which is the excitation of the analyte atoms with a highenergy electron beam (probe) with simultaneous registration of the characteristic X-ray radiation of the atoms that make up this substance. The microanalyzer operates on the energy dispersive principle, according to which all sections of the X-ray spectrum are recorded simultaneously. To implement this principle, the microanalyzer is equipped with an ultra-thin SATW entrance window for registration of light elements, starting with carbon. Structurally, the microanalyzer includes a main unit with an X-max 80 detector based on an energy dispersive spectrometer and a control unit. A silicon drift detector is used to detect the characteristic X-ray radiation of the microanalyzer. The microanalyzer operation is controlled and the measurement data is processed using an IBM PC type computer and a specialized analytical software system, Aztec, while information on the mass fractions of the analyzed elements is displayed on the microanalyzer monitor.

\section{Radiation therapy}

In the Yakutsk Republican Oncological Dispensary (Yakutsk, Russia), patients received radiation therapy, which consists of two stages: first, external beam therapy using an Elekta Synergy accelerator (United Kingdom, external beam radiation therapy, 6-18 MeV), and then brachytherapy using the MultiSourse HDR device (Germany, brachytherapy with Cobalt-60 source). At the first stage, treatment was performed on a linear accelerator in the mode of working with electrons with energy of $6 \mathrm{MeV}$. The therapy was carried out as follows: 3 times for 5 days daily with a break of 2 days (i.e. at the first stage only 15 fractions of $2 \mathrm{~Gy}$ were carried out). Then, without a break between the first and second stage, contact
RT of $5 \mathrm{~Gy}$ was performed, interspersed with distanced RT of $2 \mathrm{~Gy}$ of 5 fractions of each type of RT. Blood samples were collected at the beginning, middle, and end of external beam therapy, then at the middle and at the end of contact radiation therapy. Multiple methods (3D CRT, IMRT, VMAT) were employed in the course of therapy to ensure precision delivery of high doses to the tumor and low doses to healthy tissue.

The study was conducted in accordance with ethical principles of the WMA Declaration of Helsinki (1964, ed. 2013) and approved by the Ethics Committee of the M.K. Ammosov North-Eastern Federal University (protocol No. 13 of April 4, 2018, decision No. 2). Written informed consent was obtained from each patient.

\section{Primary methods for processing experimental results}

To determine the elemental composition of EV and NP, as well as the RBC surface without nanosized objects, we used SEM images obtained at 40,000x magnification and at a working distance of $10 \mathrm{~mm}$. Primary methods of statistical processing of experimental data were used to determine the percentage of the weight ratio of chemical elements of nanosized objects. The program displays on the monitor histograms of the weight ratio of the elements of the objects under study. Based on these histograms, the weight distribution of the elements was determined as a Gaussian normal distribution, which was verified using the Shapiro-Wilk test.

\section{Results and Discussion}

This paper presents the results of examining blood samples of a 38-year-old female patient, who is one of the patients diagnosed with CC. To determine the elemental composition of NP-objects, which were conventionally divided into NP-EV and NP-V, we used SEM images of these objects with a magnification of 40,000x and an accelerating voltage of $1-2 \mathrm{kV}$ (Fig.1).

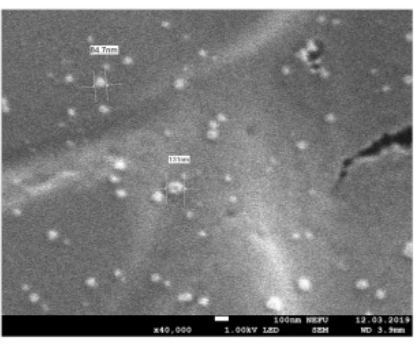

(A)

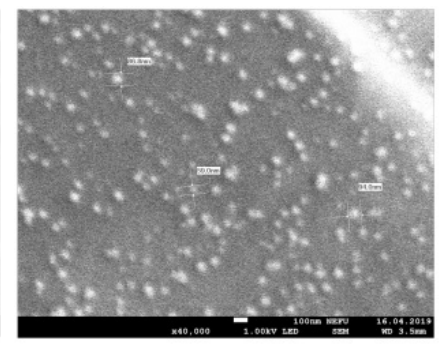

(B)
Fig. 1. NP-objects on the RBC surface before (A) and during (B) RT in a blood sample from a patient with $C C$ (magnification of 40,000x, an accelerating voltage of $1 \mathrm{kV}$ ).

NP-Vs found on the surface of erythrocytes before RT have sharper contours and are much smaller than NP-Vs arising during RT. NP-EVs, that arise during RT, are evenly distributed not only on the surface of erythrocytes, but are also found in plasma. The amount of NP-Vs in some samples decreases during RT, while NP-EVs were detected precisely during RT and their number both increased and decreased during RT. The distribution of the linear dimensions of the NP-EVs corresponds to the Gaussian distribution, i.e. have a normal 
distribution over one range, while NP-Vs are characterized by a discrete distribution, i.e. the linear dimensions of NP-Vs are different in several characteristic ranges, where they have the form of a Gaussian distribution. Also, the number of NP-Vs having different linear dimensions differs significantly.

To determine the elemental composition of a nanoscale object using SEM, the accelerating voltage equal to $2 \mathrm{kV}$ was chosen, and the beam was directed to the nanoparticles at a magnification of $40,000 x$. In the course of the study, the elemental composition of $13 \mathrm{NP}$ was obtained for one sample of the patient's blood before and after RT. For example, in Fig. 2, the area of aiming the beam on the NP-EV is indicated and its elemental composition is presented.

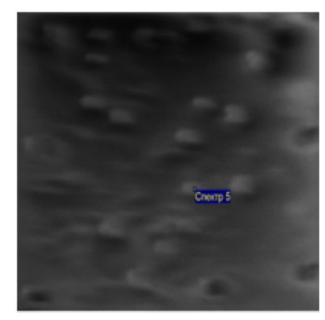

(A)

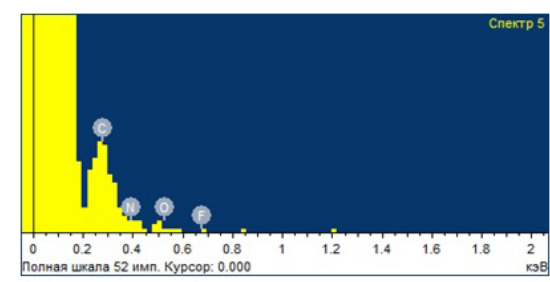

(B)
Fig. 2. (A) An NP-EV is selected for the study of the elemental composition; $(B)$ The energy spectrum of the $N P$ specified in $(A)$.

In one of the samples, the spectra of 13 NPs were obtained. Figure 3 shows a histogram of the elemental weight composition of an NP-object in percent on average.

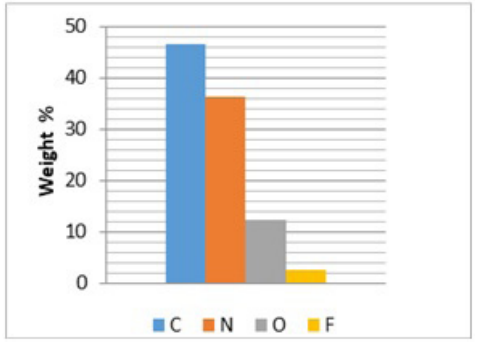

(A)

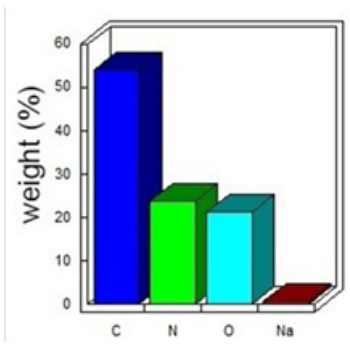

(B)
Fig. 3. Histogram of the average elemental weight composition of NPS in percent: $(A)-N P-V E ;(B)-N P-V$.

From our data, it follows that the composition of NPs is approximately the same, which corresponds to the literature data. It is known that the atomic composition is approximately the same in cell vesicles and virus capsids, including HPV16 and HPV18, since they are composed of proteins. ${ }^{(23-29)}$

Using PCR of the erythrocyte mass of blood samples from CC patients before RT, we found that HPV DNA was detected in $41.7 \%$ of samples $(16.7 \%$ in plasma, $25 \%$ in $\mathrm{Et}+$ ), and the $\beta$-globin gene was found in $66,7 \%$ of samples ( $16.7 \%$ in plasma, $33.3 \%$ in Et+, and $16.7 \%$ in Et-). SEM studies of the same blood samples revealed the presence of NPs on the RBC surface. The number of NPs on the RBC surface was higher than in plasma. It is known ${ }^{(30)}$ that some viruses trigger the formation of vesicles on the cell surface during infection. It is likely that the correlation between the number of viruses detected by SEM and vesicles on the cell surface may be the basis for the formation of new diagnostic methods and screening of vaccines. Proliferative cancer cells show an increase in cancer tissue as a result of angiogenesis, the acquisition of migratory and invasive abilities, and the acquisition of the ability to avoid attacks by immune cells and, ultimately, the formation of metastatic lesions. It is known that exosomes are involved in each of these processes. ${ }^{(31)}$ In the blood, exosomes can appear from various cells; tumors are the maximum producers of exosomes $\left(10^{9}\right.$ vesicles $/ \mathrm{mL}$ in the blood), which correlates with their role in carcinogenesis. The relationship between circulating exosomes and tumor cells can be described as "seeds and plants." Exosomes obtained from tumor cells that carry different genetic material are released into the bloodstream. Some exosomes spread to distant organs and transform organ cells into tumor cells by transferring the bioactive component to the recipient cell. In addition to an increase in the number of circulating exosomes in the blood of cancer patients, their differences in size and morphology were revealed. For example, it was shown that the sizes of exosomes in serum obtained from patients with pancreatic adenocarcinoma were significantly smaller than those in healthy donors. Also, atomic force microscopy revealed the morphological and molecular differences between exosomes of healthy people and patients with oral cancer. ${ }^{(32)}$ Based on a number of studies ${ }^{(30-43)}$ that examine the relationship of viruses associated with certain cancers and exosomes it can be assumed that the observed increase in the number of vesicles in this study during RT in some patients may be triggered by the effect of radiation on tumor cells. Indeed, in the work of Mata-Rocha et al., ${ }^{(44)}$ it was found that not only exosomes obtained from HeLa cells contained HPV DNA, but also non-malignant, HPV-positive, cervical specimens with and without squamous intraepithelial lesions had HPV DNA(including E6 and E7 oncogenes). These findings point to another potential source of erythrocyte-associated EV in patients with CC: non-infectious HPV cells. Although it is likely that erythrocyte-associated EV in CC patients can be attributed to cancer cells or HPV-infected cells, the possibility that they are produced by changes in erythrocytes cannot be ruled out. This is evidenced by the fact that the diameter of the detected EV $(69.91 \pm 12.15 \mathrm{~nm})^{(1)}$ closely matches the size of erythrocyte exosomes described by Huang et al.. ${ }^{(45)}$ Probably, erythrocytes release vesicles into the extracellular space in normal conditions, but this process is enhanced in pathology. ${ }^{(46)}$

The role of this process in the formation of pathological conditions, including CC, has not been sufficiently studied. However, exosomes have been shown to modulate the immune response by increasing the proliferation of T-cells in an antigen-presenting, cell-dependent manner. ${ }^{(47)}$ In fact, the number of T-cells was increased by more than $50 \%$ compared with phytohemagglutinin stimulation alone. In addition, EVs formed on the surface of erythrocytes can be involved in inflammation and stimulate the synthesis of pro-inflammatory cytokines in peripheral blood mononuclear cells. ${ }^{(47)}$ 
In accordance with the literature data and the results of our studies, the number of NPs on the RBC surface increased, possibly due to the pathology of erythrocytes under the influence of viruses. The secretion of exosomes from erythrocytes, in turn, can also be enhanced by exposure to radiation.

In the course of this study, we monitored the condition of this patient, in whom the greatest increase in the number of NPEVs was observed after RT for 1.5 years. During this period, courses of chemotherapy and drug therapy were carried out; however, during this period, in comparison with other patients, this patient underwent a relapse and a more aggressive further development of the disease with concomitant complications.

In conclusion, the results of this study using SEM and the PCR method indicate that the formation of NP observed before exposure to ionizing radiation can be caused by various processes, namely, the effect of viruses and the formation of vesicles on the cell surface as a result of the disease. PCR analysis of blood samples from patients with $\mathrm{CC}$ before RT revealed the presence of HPV DNA in some samples. An increase in the number of EV on the surface of erythrocytes and in plasma during RT indicates the formation of exosomes is activated by both cancer cells themselves and by erythrocytes under the influence of ionizing radiation. In addition, it is also assumed that viruses detected on the surface can more intensively stimulate the formation of vesicles on the surface of erythrocytes during RT.

Further observation of patients with $\mathrm{CC}$ after RT shows that an increase in the number of vesicles in the blood may be associated with a negative prognosis related to a relapse of the disease, i.e. about the low efficiency of RT. In addition, a slight decrease in the NP-V number during RT may also indicate a slight effect of RT on NP-V.

It is obvious that further examination of the blood of patients during RT will make it possible to reveal the quantitative ratio of these NPs before and after each stage of RT to determine the criterion (critical ratio) of the effectiveness of therapy. Thus, the complex technique for examining the blood of CC patients, considered in this work, can become the basis for developing a methodology for determining the effectiveness of RT, as well as form the basis for further studies of the role of viruses, vesicles, and erythrocytes in the development of CC.

\section{Acknowledgments}

This study was supported by "The Fund of Target Capital Management North-Eastern Federal University named after M. K. Ammosov"; Georgy V. Maksimov acknowledge financial support from Russian Sciences Foundation (grant RSF 19-79-30062).

\section{Competing Interests}

The authors declare that they have no competing interests.

*Corresponding author: Irina V. Kononova, PhD. Yakut Scientific Center of Complex Medical Problems, Yakutsk, Russia. E-mail: irinakon.07@,mail.ru

\section{References}

1. Mamaeva SN, Maksimov GV, Antonov SR, Neustroev EP, Kononova IV, Zakharova, et al. Studying of erythrocytes of blood during radiation therapy in cases of cancer of neck of an uterus with application of methods of medical physics and nanobiotechnologies. AIP Conference Proceedings 2041, 050016 (2018); doi: 0.1063/1.5079385.

2. Mamaeva SN, Kononova IV, Ruzhansky M, Nikiforov PV, Nikolaeva NA; Pavlov AN, et al. Using Scanning Electron Microscopy and Atomic Force Microscopy to Study the Formation of Nanoparticles on Red Blood Cell Surface in Cervical Cancer Patients. International Journal of Biomedicine. 2020;10(1):70-75. doi: 10.21103/Article10(1) OA12.

3. Kim HK, Song KS, Park YS, Kang YH, Lee YJ, Lee KR, et al. Elevated levels of circulating platelet microparticles, VEGF, IL-6 and RANTES in patients with gastric cancer: possible role of a metastasis predictor. Eur J Cancer. 2003 Jan;39(2):184-91. doi: 10.1016/s0959-8049(02)00596-8. Erratum in: Eur J Cancer. 2003 Nov;39(17):2569.

4. Liu J, Sun H, Wang X, Yu Q, Li S, Yu X, Gong W. Increased exosomal microRNA-21 and microRNA-146a levels in the cervicovaginal lavage specimens of patients with cervical cancer. Int J Mol Sci. 2014 Jan 8;15(1):758-73. doi: 10.3390/ijms15010758.

5. Jang SC, Kim SR, Yoon YJ, Park KS, Kim JH, Lee J, et al. YS. In vivo kinetic biodistribution of nano-sized outer membrane vesicles derived from bacteria. Small. 2015 Jan 27;11(4):456-61. doi: 10.1002/smll.201401803.

6. EL Andaloussi S, Mäger I, Breakefield XO, Wood MJ. Extracellular vesicles: biology and emerging therapeutic opportunities. Nat Rev Drug Discov. 2013 May;12(5):347-57. doi: $10.1038 / \operatorname{nrd} 3978$.

7. Mangino G, Chiantore MV, Luliano M, Capriotti L, Accardi L, Bonito PD, et al. Role of Extracellular Vesicles in Human Papillomavirus-Induced Tumorigenesis. In: Saxena SK, editor. Current Perspectives in Human Papillomavirus. IntechOpen. 2018;5:1-21. doi: 10.5772/intechopen.80654.

8. Taylor DD, Gercel-Taylor C. MicroRNA signatures of tumor-derived exosomes as diagnostic biomarkers of ovarian cancer. Gynecol Oncol. 2008 Jul;110(1):13-21. doi: 10.1016/j. ygyno.2008.04.033. Erratum in: Gynecol Oncol. 2010 Jan;116(1):153.

9. Keller S, König AK, Marmé F, Runz S, Wolterink S, Koensgen D, et al. Systemic presence and tumor-growth promoting effect of ovarian carcinoma released exosomes. Cancer Lett. 2009 Jun 8;278(1):73-81. doi: 10.1016/j. canlet.2008.12.028.

10. Chai H, Brown RE. Field effect in cancer-an update. Ann Clin Lab Sci. 2009 Fall;39(4):331-7. PMID: 19880759.

11. Honegger A, Schilling D, Bastian S, Sponagel J, Kuryshev V, Sültmann H, et al. Dependence of intracellular and exosomal microRNAs on viral E6/E7 oncogene expression in HPV-positive tumor cells. PLoS Pathog. 2015 Mar 11;11(3):e1004712. doi: 10.1371/journal.ppat.1004712. 12. Li H, Chi X, Li R, Ouyang J, Chen Y. HIV-1-infected cell-derived exosomes promote the growth and progression of cervical cancer. Int J Biol Sci. 2019 Sep 7;15(11):2438-2447. doi: 10.7150/ijbs.38146.

13. Al-Mayah A, Bright S, Chapman K, Irons S, Luo P, Carter D, Goodwin E, Kadhim M. The non-targeted effects of radiation are perpetuated by exosomes. Mutat Res. 2015 
Feb;772:38-45. doi: 10.1016/j.mrfmmm.2014.12.007.

14. Arscott WT, Tandle AT, Zhao S, Shabason JE, Gordon IK, Schlaff CD, Zhang G, Tofilon PJ, Camphausen KA. Ionizing radiation and glioblastoma exosomes: implications in tumor biology and cell migration. Transl Oncol. 2013 Dec 1;6(6):638-48. doi: 10.1593/tlo.13640.

15. Mutschelknaus L, Peters C, Winkler K, Yentrapalli R, Heider T, Atkinson MJ, Moertl S. Exosomes Derived from Squamous Head and Neck Cancer Promote Cell Survival after Ionizing Radiation. PLoS One. 2016 Mar 23;11(3):e0152213. doi: 10.1371/journal.pone.0152213.

16. Mutschelknaus L, Azimzadeh O, Heider T, Winkler K, Vetter M, Kell R, Tapio S, Merl-Pham J, Huber SM, Edalat L, Radulović V, Anastasov N, Atkinson MJ, Moertl S. Radiation alters the cargo of exosomes released from squamous head and neck cancer cells to promote migration of recipient cells. Sci Rep. 2017 Sep 29;7(1):12423. doi: 10.1038/s41598-01712403-6.

17. Snijders PJ, van den Brule AJ, Schrijnemakers HF, Snow G, Meijer CJ, Walboomers JM. The use of general primers in the polymerase chain reaction permits the detection of a broad spectrum of human papillomavirus genotypes. J Gen Virol. 1990;71 (1):173-81. doi: 10.1099/0022-1317-71-1-173. PMID: 2154534.

18. de Roda Husman AM, Walboomers JM, van den Brule AJ, Meijer CJ, Snijders PJ. The use of general primers GP5 and GP6 elongated at their 3' ends with adjacent highly conserved sequences improves human papillomavirus detection by PCR. J Gen Virol. 1995;76(4):1057-62. doi: 10.1099/0022-131776-4-1057. PMID: 9049358.

19. Bosch FX, Manos MM, Muñoz N, Sherman M, Jansen AM, Peto J, Schiffman MH, Moreno V, Kurman R, Shah $\mathrm{KV}$. Prevalence of human papillomavirus in cervical cancer: a worldwide perspective. International biological study on cervical cancer (IBSCC) Study Group. J Natl Cancer Inst. 1995;87(11):796-802. doi: 10.1093/jnci/87.11.796. PMID: 7791229.

20. Fuessel Haws AL, He Q, Rady PL, Zhang L, Grady J, Hughes TK, Stisser K, Konig R, Tyring SK. Nested PCR with the PGMY09/11 and GP5(+)/6(+) primer sets improves detection of HPV DNA in cervical samples. J Virol Methods. 2004;122(1):87-93. doi: 10.1016/j.jviromet.2004.08.007. PMID: 15488625 .

21. Cope JU, Hildesheim A, Schiffman MH, Manos MM, Lörincz AT, Burk RD, Glass AG, Greer C, Buckland J, Helgesen K, Scott DR, Sherman ME, Kurman RJ, Liaw KL. Comparison of the hybrid capture tube test and PCR for detection of human papillomavirus DNA in cervical specimens. J Clin Microbiol. 1997;35(9):2262-2265. doi:10.1128/JCM.35.9.2262-2265.1997.

22. Shah KV, Daniel RW, Simons JW, Vogelstein B. Investigation of colon cancers for human papillomavirus genomic sequences by polymerase chain reaction. J Surg Oncol. 1992;51(1):5-7. doi: 10.1002/jso.2930510104. PMID: 1325576.

23. Conway MJ, Meyers C. Replication and assembly of human papillomaviruses. J Dent Res. 2009 Apr;88(4):307-17. doi: 10.1177/0022034509333446.

24. Buck CB, Cheng N, Thompson CD, Lowy DR, Steven AC, Schiller JT, Trus BL. Arrangement of L2 within the papillomavirus capsid. J Virol. 2008 Jun;82(11):5190-7. doi: 10.1128/JVI.02726-07.

25. Schiller JT, Lowy DR. Understanding and learning from the success of prophylactic human papillomavirus vaccines.
Nat Rev Microbiol. 2012 Oct;10(10):681-92. doi: 10.1038/ nrmicro2872.

26. Doorbar J, Gallimore PH. Identification of proteins encoded by the L1 and L2 open reading frames of human papillomavirus 1a. J Virol. 1987 Sep;61(9):2793-9. doi: 10.1128/JVI.61.9.2793-2799.1987.

27. Klimov E, Sobolev V, Solov'ev AM, Perlamutrov $\mathrm{Yu}$, Korsunskaya I. Proteins and microRNA participating in papillomavirus imfection. RUDN Journal of Medicine. 2018;22:43-49. doi:10.22363/2313-0245-2018-22-1-43-49.

28. WHO. Human papillomavirus. Available from: https:// www.who.int/biologicals/vaccines/human_papillomavirus $\mathrm{HPV} / \mathrm{en} /$

29. Cooper GM. The Cell: A Molecular Approach. 2nd edition. Sunderland (MA): Sinauer Associates; 2000. Structure of the Plasma Membrane. Available from: https://www.ncbi.nlm.nih. gov/books/NBK9898/

30. Hugel B, Martínez MC, Kunzelmann C, Freyssinet JM. Membrane microparticles: two sides of the coin. Physiology (Bethesda). 2005 Feb;20:22-7. doi: 10.1152/ physiol.00029.2004.

31. Doyle LM, Wang MZ. Overview of Extracellular Vesicles, Their Origin, Composition, Purpose, and Methods for Exosome Isolation and Analysis. Cells. 2019 Jul 15;8(7):727. doi: $10.3390 /$ cells 8070727 .

32. Meckes DG Jr, Raab-Traub N. Microvesicles and viral infection. J Virol. 2011 Dec;85(24):12844-54. doi: 10.1128/ JVI.05853-11.

33. Osaki M, Okada F. Exosomes and Their Role in Cancer Progression. Yonago Acta Med. 2019 Jun 20;62(2):182-190. doi: 10.33160/yam.2019.06.002.

34. Meng X, Pan J, Sun S, Gon Z. Circulating exosomes and their cargos in blood as novel biomarkers for cancer. Translational Cancer Research. 2017;7(2):226-242. https://tcr. amegroups.com/article/view/16197.

35. Hood JL, Pan H, Lanza GM, Wickline SA; Consortium for Translational Research in Advanced Imaging and Nanomedicine(C-TRAIN). Paracrine induction of endothelium by tumor exosomes. Lab Invest. 2009 Nov;89(11):1317-28. doi: 10.1038/labinvest.2009.94.

36. Kalluri R. The biology and function of exosomes in cancer. J Clin Invest. 2016 Apr 1;126(4):1208-15. doi: 10.1172/JCI81135.

37. Soung YH, Ford S, Zhang V, Chung J. Exosomes in Cancer Diagnostics. Cancers (Basel). 2017 Jan 12;9(1):8. doi: 10.3390/cancers9010008.

38. Mizutani K, Terazawa R, Kameyama K, Kato T, Horie $\mathrm{K}$, Tsuchiya $\mathrm{T}$, et al. Isolation of prostate cancer-related exosomes. Anticancer Res. 2014 Jul;34(7):3419-23.

39. Skog J, Würdinger T, van Rijn S, Meijer DH, Gainche L, Sena-Esteves M, et al. Glioblastoma microvesicles transport RNA and proteins that promote tumour growth and provide diagnostic biomarkers. Nat Cell Biol. 2008 Dec;10(12):14706. doi: $10.1038 /$ ncb1800.

40. Clayton A, Turkes A, Dewitt S, Steadman R, Mason MD, Hallett MB. Adhesion and signaling by B cell-derived exosomes: the role of integrins. FASEB J. 2004 Jun;18(9):9779. doi: 10.1096/fj.03-1094fje.

41. Fu Q, Zhang Q, Lou Y, Yang J, Nie G, Chen Q, Chen Y, Zhang J, Wang J, Wei T, Qin H, Dang X, Bai X, Liang T. Primary tumor-derived exosomes facilitate metastasis by regulating adhesion of circulating tumor cells via SMAD3 in liver cancer. Oncogene. 2018 Nov;37(47):6105-6118. doi: 
10.1038/s41388-018-0391-0. Epub 2018 Jul 10. Erratum in: Oncogene. 2019 Jul;38(28):5740-5741.

42. Fang DY, King HW, Li JY, Gleadle JM. Exosomes and the kidney: blaming the messenger. Nephrology (Carlton). 2013 Jan;18(1):1-10. doi: 10.1111/nep.12005.

43. van Doormaal FF, Kleinjan A, Di Nisio M, Büller HR, Nieuwland R. Cell-derived microvesicles and cancer. Neth J Med. 2009 Jul-Aug;67(7):266-73.

44. Mata-Rocha M, Rodríguez-Hernández RM, ChávezOlmos P, Garrido E, Robles-Vázquez C, Aguilar-Ruiz S, et al. Presence of HPV DNA in extracellular vesicles from HeLa cells and cervical samples. Enferm Infecc Microbiol Clin. 2020 Apr;38(4):159-165. English, Spanish. doi: 10.1016/j. eimc.2019.06.011.
45. Huang H, Zhu J, Fan L, Lin Q, Fu D, Wei B, Wei S. MicroRNA Profiling of Exosomes Derived from Red Blood Cell Units: Implications in TransfusionRelated Immunomodulation. Biomed Res Int. 2019 Jun 13;2019:2045915. doi: 10.1155/2019/2045915.

46. Harisa GI, Badran MM, Alanazi FK. Erythrocyte nanovesicles: Biogenesis, biological roles and therapeutic approach: Erythrocyte nanovesicles. Saudi Pharm J. 2017 Jan;25(1):8-17. doi: 10.1016/j.jsps.2015.06.010.

47. Danesh A, Inglis HC, Jackman RP, Wu S, Deng X, Muench MO, Heitman JW, Norris PJ. Exosomes from red blood cell units bind to monocytes and induce proinflammatory cytokines, boosting T-cell responses in vitro. Blood. 2014 Jan 30;123(5):687-96. doi: 10.1182/blood-2013-10-530469. 